\title{
Seasonal and Interannual Variation in Energy Balance in the Semiarid Grassland Area of China
}

\author{
Qun'ou Jiang, ${ }^{1}$ Enjun $\mathrm{Ma}^{2}{ }^{2}$ Jinyan Zhan, ${ }^{3}$ and Nana Shi ${ }^{4}$ \\ ${ }^{1}$ School of Soil and Water Conservation, Beijing Forestry University, Beijing 100038, China \\ ${ }^{2}$ School of Mathematics and Physics, China University of Geosciences, Wuhan 430074, China \\ ${ }^{3}$ State Key Laboratory of Water Environment Simulation, School of Environment, Beijing Normal University, Beijing 100875, China \\ ${ }^{4}$ Chinese Research Academy of Environmental Sciences, Beijing 100012, China \\ Correspondence should be addressed to Qun’u Jiang; jiangqo.dls@163.com
}

Received 18 May 2014; Accepted 15 July 2014

Academic Editor: Huiwang Gao

Copyright ( 2015 Qun'ou Jiang et al. This is an open access article distributed under the Creative Commons Attribution License, which permits unrestricted use, distribution, and reproduction in any medium, provided the original work is properly cited.

\begin{abstract}
Near surface energy budget changes have been proved to be induced by the land cover conversion through changing the surface physical properties, which can further impact the regional climate change. This study applies the DLS model to simulate the land cover under the business as usual (BAU) scenario and then analyses the seasonal and interannual variation of energy balance in the semiarid grassland area of China based on the simulated land cover with the Weather Research and Forecasting (WRF) model. The results indicate that the grassland will show a growing trend under the BAU scenario. Downward long wave radiation and downward short wave radiation will all have small-scale increase with time going by, while the surface net radiation will decrease from 2030 to 2050. However, there is obvious seasonal variation. Summer has the highest downward long wave radiation and downward short wave radiation, followed by spring and autumn. The lowest are in winter. As for the net surface radiation, there is obvious decrease in southeast of study area due to returning cropland to grassland. Those research conclusions can offer valuable information for the land use planning and relieving the effects of land cover change on climate change at the semiarid grassland area.
\end{abstract}

\section{Introduction}

Net surface radiation refers to the net surface energy produced in the process of short wave radiation and long wave radiation, which controls the sensible heat and latent heat flux emitted into the atmosphere, and it is a significant component of surface energy budget [1-5]. Therefore, it is the driving force for the transport and exchange of ground energy and material and plays a key role in the earth-atmosphere system. Some studies have found that the global net surface radiation has shown the downward trend since $1980[6,7]$. Temporal and spatial variation of net surface radiation brings about effect not only on the regional climate, but also on the surface evapotranspiration and the structure of regional ecosystems to some extent $[8,9]$. China has complex weather patterns and ecosystem types; therefore, it is significant to study the spatial characteristics of net surface radiation for the regional plant growth, global warming, and human activities.
Surface radiation has been proved to be influenced by the land cover and the IPCC fourth assessment report also pointed out that the change of the underlying surface is one of the main driving forces for the surface energy balance [10-14]. Since the industrial revolution, human activities have caused a wide range of changes in land use/land cover. Previous researches indicate that about $40 \%$ of the global land surface has been affected by human activities, including the conversion from the ecological land to the cultivated land or urban area [15]. Land use change caused by human activities can have the influence not only at the regional scale, but also at larger scale or even the global scale through the biogeophysical, biogeochemical cycle process [16-19]. Additionally, there is obvious seasonal and interannual variation, the variation in the history has been studied, and it is inevitable that land cover change will continue in the future. How does the land cover change impact the land surface energy balance in the future has become a hot issue in the global change researches. 
Arid and semiarid areas account for more than $40 \%$ of China's land area, and midlatitude semiarid grassland is one significant type of global terrestrial ecosystem. Because of the special vegetation, soil, and albedo in semiarid grassland, the surface radiation balance in arid areas is different from that in humid areas. The external forcing for the atmosphere in semiarid grassland is therefore different [20-24]. Domestic scholars began working on the energy balance studies in semiarid regions since the 1980 s and had organized a series of large-scale field trials for the land surface processes, such as land surface processes experiment at Heihe River Basin (HEIFE), Inner Mongolia semiarid grassland soil-vegetationatmosphere interaction (IMGRASS), and field experiment on interaction between land and atmosphere in arid region of Northwest China (NWC-ALIEX) [22-24]. These studies were mainly for the historical period and most of them are observed by the experiment; however, there are few on the surface energy balance under the future scenarios and those cannot be observed any more. The Weather Research and Forecasting (WRF) model is one of the popular models for simulating the surface energy; therefore, this study selects the WRF model to simulate the surface energy variation based on the land cover spatial distribution.

In order to deeply understand the radiation force in the semiarid grassland region, this paper selects the Loess Plateau as the study area which is located in Western China and includes Shaanxi Province, Ningxia Hui Autonomous Region, Shanxi Province, Gansu Province Southern part of Inner Mongolia Autonomous Region, Eastern part of Qinghai Province, and Western part of Henan Province (Figure 1). Firstly, the land cover is simulated with the DLS (dynamics of land system) model and then the simulated results are processed in accordance with the requirements of underlying surface of WRF (Weather Research and Forecast) model. Finally, the seasonal and interannual variations of the surface radiation under the future scenarios in the semiarid grassland area are analyzed by the WRF model. The results will provide the scientific basis for the rational land use planning and the climate change mitigation.

\section{Data and Methodology}

2.1. Data Source. The data applied in this study consists of land cover data, forcing data, and the data relative to the natural environment and socioeconomics. Among them, the land cover data with $1 \mathrm{~km}$ resolution in 2010 is extracted from the USGS remote sensing images and includes 24 types which comply with the USGS classification system. The land cover data from 2010 to 2050 is simulated by the DLS model based on the designed scenario, and then the $1 \mathrm{~km}$ resolution land cover data is resampled into the $10 \mathrm{~km}$ resolution data according to the requirement of the WRF model.

Forcing data is applied in the WRF model and it includes wind field, surface air temperature, long wave radiation, short wave radiation, and so on. All of the forcing data is derived from the dataset of the fifth phase of the Climate Model Intercomparison Project (CMIP5) which consists of 29 global climate models, and this study uses the dataset of Geophysical Fluid Dynamics Laboratory CM3 (GFDLCM3) model. This kind of model has four Representative Concentration Pathways (RCPs) scenarios such as RCP2.6, RCP4.5, RCP6.0, and RCP8.5, and this study analyzes the energy status under the RCP6.0 scenarios.

Natural environment condition data and social and economic statistical data are used in the DLS model. Natural environment condition data contains DEM, terrain slope, organic content of soil, and location data such as the distance to the railway and highway and the distance to the river. The terrain slope is derived from the DEM data at a scale of $1: 250,000$. Organic content of soil comes from the national soil survey of China. The location data is calculated by using measuring tools based on the road network, water area map. Social-economic data includes population, GDP, and the total investment in fixed assets, which comes from the National Statistical Yearbook.

2.2. WRF Model. The research version of the WRF model, namely, ARW (Advanced Research WRF), is used to analyze the impacts of land use/cover change on the surface radiation in this study. The WRF model is a next-generation mesoscale model, which can estimate the energy exchanges between the land surface and atmosphere from the view of water balance and energy balance with the Noah land surface parameterization scheme in the WRF model [25-27]. To simulate the spatial distribution of net surface radiation more accurately, this study uses three-layer nested structure, and the area ratio of three layers is $3: 2: 1$. The input parameters such as air temperature, sea ice, and soil moisture are updated every day, and another significant input parameter is the land cover dataset and the one in 2010 is used as the baseline underlying surface data to simulate the effects of land cover change on the surface radiation. The long wave radiation scheme and shortwave radiation scheme were RRTM and Dudhia, respectively. The boundary layer process scheme was YSU, and the land surface process scheme was Noah land surface model.

2.3. Estimation for the Net Surface Radiation. According to the surface energy budget equation, the net surface radiation is estimated by land surface albedo, downward short wave radiation, downward long wave radiation, temperature, and land surface emissivity [28]:

$$
R_{n}=R_{n}^{S}+R_{n}^{l}=(1-\alpha) F_{d}^{s}+\varepsilon F_{d}^{l}-\sigma \varepsilon T^{4},
$$

where $R_{n}$ is the surface net radiation, $R_{n}^{S}$ is the shortwave radiation, $R_{n}^{l}$ is the long wave radiation, $\alpha$ is the albedo of the surface, $F_{d}^{s}$ is the downward shortwave radiation, $\varepsilon$ is the long wave emissivity of the surface, $F_{d}^{l}$ is the downward long wave radiation, $T$ is the land surface temperature, and $\sigma$ is Boltzmann's constant $\left(5.67 \times 10^{-8}\right.$ Watts $\left./ \mathrm{m}^{2} / \mathrm{K}^{4}\right)$.

2.4. DLS Model. DLS model has been proved to be robust to simulate the land cover change at the pixel scale, and it is a powerful tool for analyzing the reasons, process, and results of land use dynamics and understanding its environmental 


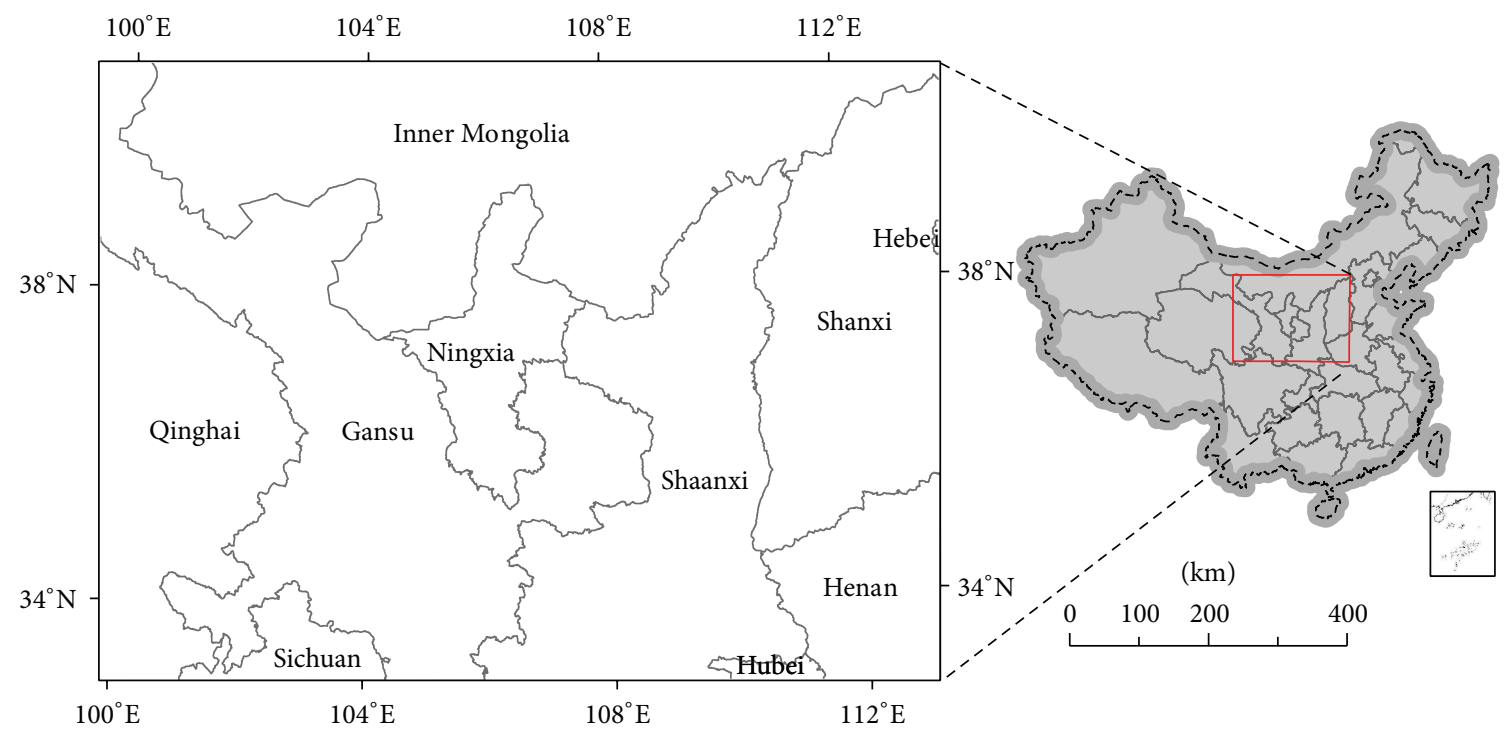

FIGURE 1: Location of the study area.

effects which can offer the useful reference for land use planning and management. This model fully considers the links to the natural, ecological, social, and economic models and takes the effects of topography, environment, trade, institutional arrangement, and land management policies into account. The theoretical basis of the DLS model is the CGE model and SD model, CGE model has a strong ability to explain the mechanism of land cover change, while SD model is more focused on land system and feedback, and it can really reveal the driving and feedback function of each factor in the nature-society-economy systems. Scenario design is one of the effective ways to improve the prediction accuracy of simulation, and it can make up for the uncertainty of land system dynamics. The simulation process includes the analysis on driving mechanism, scenario design, and spatial allocation of land cover $[29,30]$.

\section{Scenario Analysis for Land Cover Change under the BAU Scenario}

The land use conditions in the study area from 2010 to 2050 are simulated by DLS model. Firstly, the scenario, which is called business as usual (BAU) scenario, is designed according to the social-economic characteristics in the study area during the past 30 years, which can comprehensively reveal the real conditions of local production activities and economic development. In addition, it also takes the most possible changes such as population, factor endowments, and technological advances into account. Under the BAU scenario, it has the normal urbanization level, export growth, international energy prices, and technological innovation as usual.

The simulation results indicate that the area of grassland and pasture will show an upward trend from 2010 to 2050 under the BAU scenario, which will increase by $4.5 \%$, and the increasing ratio will gradually slow down. However, the spatial distribution of grassland and pasture in the study area has no disruptive changes. Comparing the land covers in different periods, it can be seen that the conversion is mainly dominated by the conversion between cropland and grassland. Most of the increased grassland is converted from cropland due to the policy of returning cropland to forestry area or grassland and is distributed in the Shanxi Province, southern Shaanxi Province, southeast of Gansu Province, and some areas of Ningxia. Some of the barren or sparsely vegetated land will be also converted to grassland or shrubland in the north and middle of the semiarid grassland area of China due to the ecological recovery construction. Of course, there will be some grassland or pastures transferred to urban area especially near the city or be reclaimed to cropland (Figure 2).

\section{Seasonal and Interannual Variation in Energy Balance}

According to the energy budget equation, it is found that downward short wave radiation and downward long wave radiation are the significant factors influencing the energy balance especially for the net surface radiation. Therefore, this study firstly analyzes the seasonal and interannual variation of downward long wave radiation and downward short wave radiation and then explores the spatial distribution changes of net surface radiation from 2030 to 2050.

4.1. Downward Short Wave Radiation. Monthly downward short wave radiation from 2010 to 2050 is simulated by the WRF model, and the seasonal variation is estimated based on the monthly values (Figure 3 ). Among them, spring is from March to May, summer is from June to August, autumn is from September to November, and winter is from December to February. The results indicate that there are significant seasonal variations for the downward short wave 


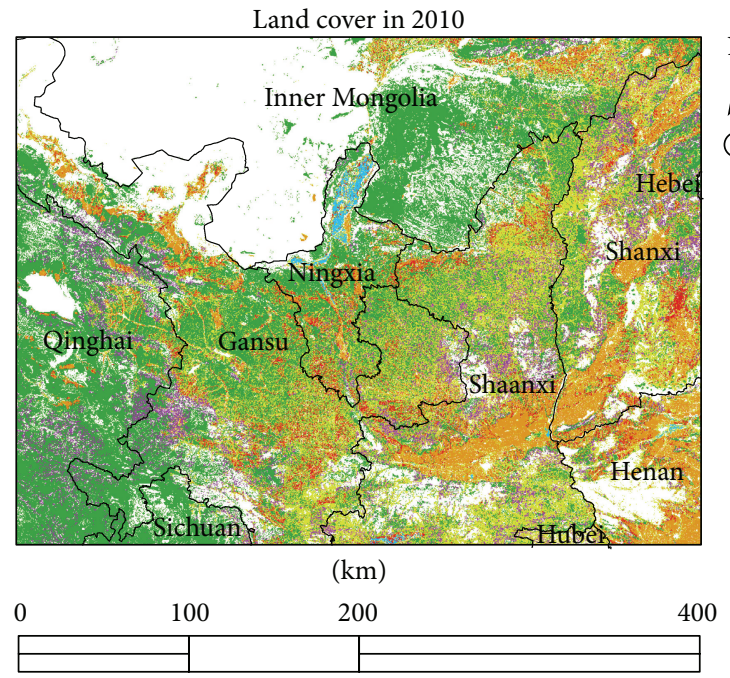

(a)

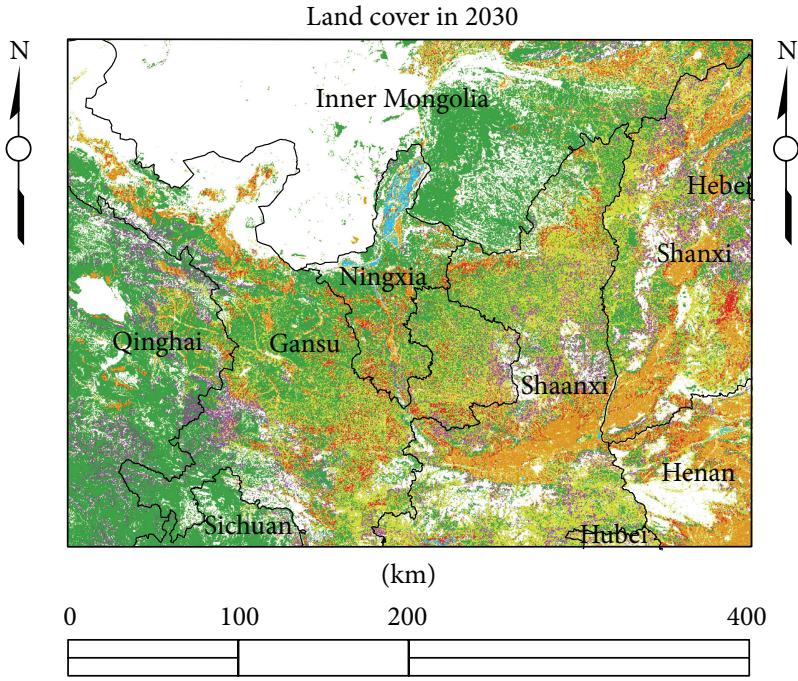

(b)

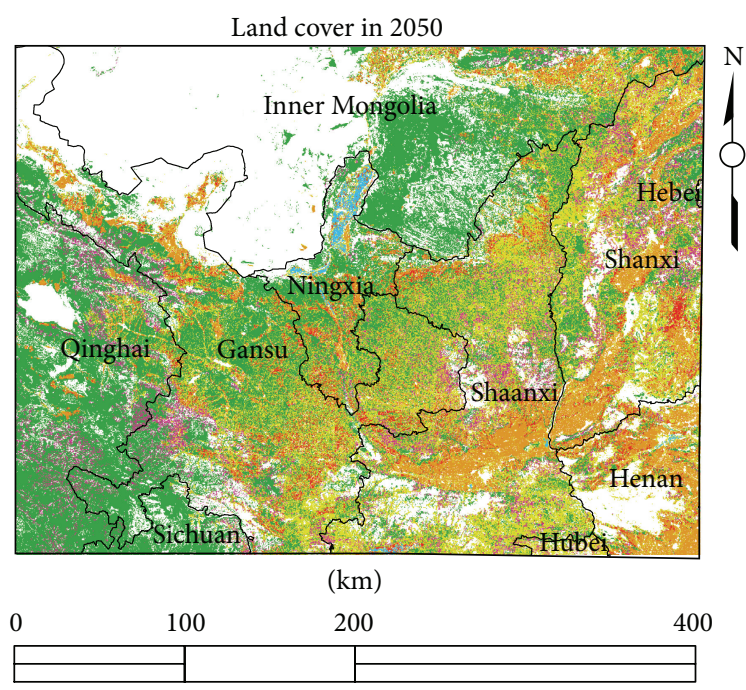

Dryland cropland and pasture

Irrigated cropland and pasture

Mixed dryland/irrigated cropland and pasture

- Cropland/grassland mosaic

Grassland

Mixed shrubland/grassland

Other kinds of land cover

(c)

FIGURE 2: Spatial distribution of grassland from 2010 to 2050.

radiation; it is highest in summer due to the vegetation growth, followed by that in spring and autumn, while the lowest is in winter, about half of that in summer. Analysis on the spatial distribution of downward short wave radiation illustrates that it is weak in the northern part of study area in winter and autumn, including Inner Mongolia Autonomous Region, northern part of Shaanxi Province, Gansu Province, Ningxia Hui Autonomous Region, and Shanxi Province, while it is stronger in the southeastern area of the study area. The downward short wave radiation shows an obvious increasing tendency from north to south, which is almost parallel to the latitude, indicating that the land cover has negligible impacts on the downward short wave radiation in winter and autumn. However, it is totally different from those in spring and summer. It is lower in Gansu Province in spring, while lower in central parts of study area in summer especially the southern part of Shaanxi Province and western part of Shanxi Province.

According to the statistics of downward short wave radiation in each grid, it can be found that the downward 


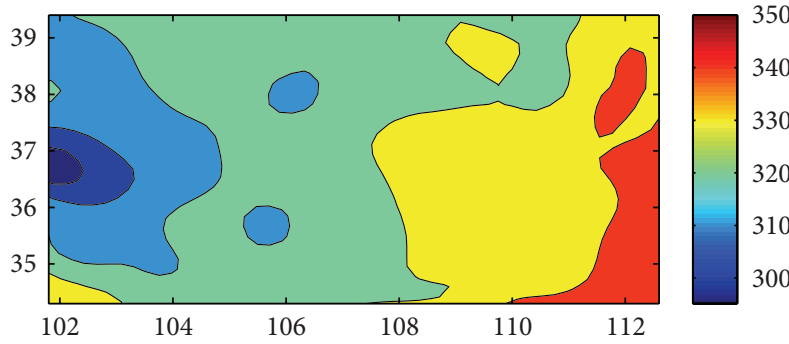

(a) Spring

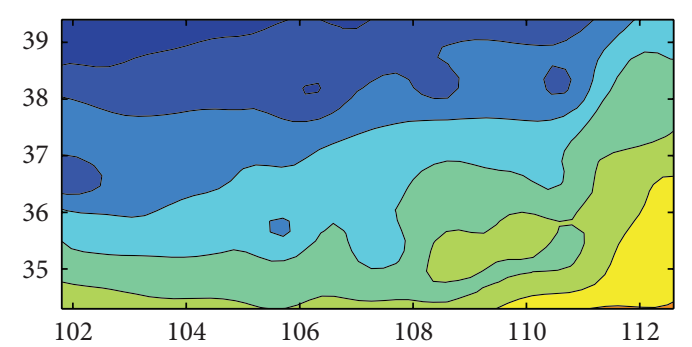

(c) Autumn

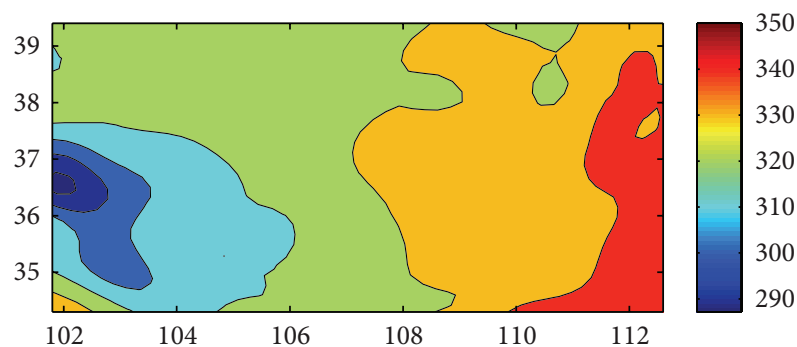

(a) Spring

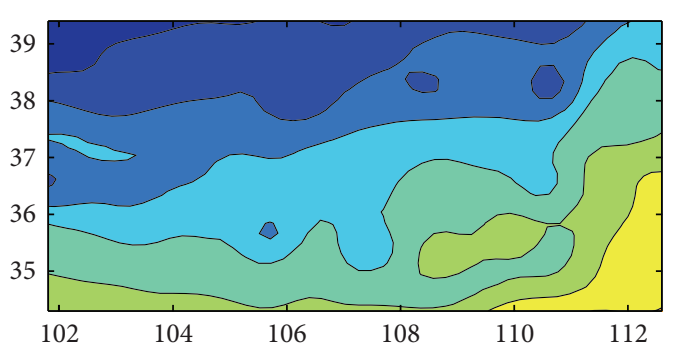

(c) Autumn
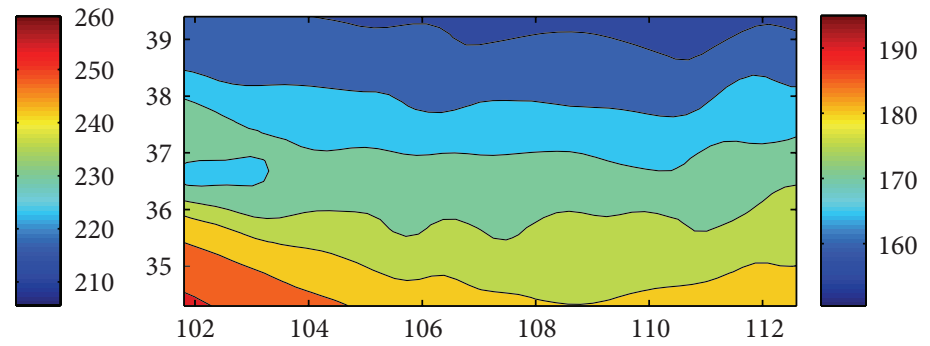

(d) Winter

(2030)

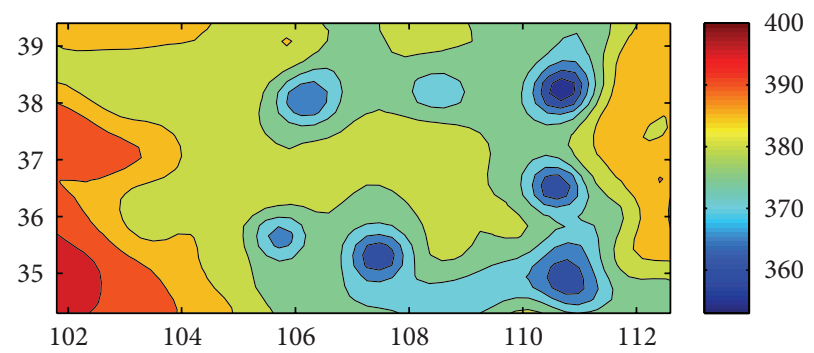

(b) Summer
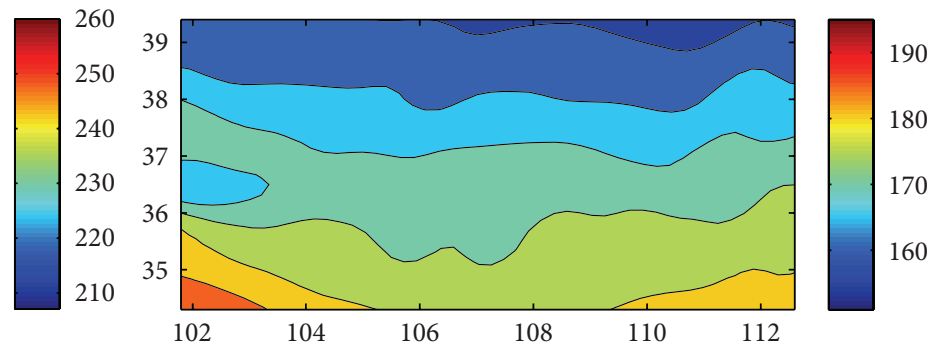

(d) Winter

(2050)

FIGURE 3: Downward short wave radiation in 2030 and 2050.

short wave radiation will have no great changes from 2010 to 2050 , which will grow from $278.6 \mathrm{~W} / \mathrm{m}^{2}$ to $281.8 \mathrm{~W} / \mathrm{m}^{2}$ under the BAU scenario. Although land cover change impacts the downward short wave radiation, the different land cover conversions have different levels of influence. Returning cropland to grassland can reduce the downward short wave radiation, but the urban area and forestry area expansion can bring about more downward short wave radiation, and that is why it has no apparent increment. However, there is remarkable seasonal variation. The downward short wave radiation in southern part of study area will increase in autumn and winter from 2030 to 2050 , while there is no obvious change in northern part. This is because the northern part of study area is covered mainly by the overlapped zone of the barren or sparsely vegetated land, while the land cover in the southeastern part is dryland cropland pasture and grassland. On the contrary, the downward short wave radiation will show a growing trend in spring and summer.

4.2. Downward Long Wave Radiation. As for the downward long wave radiation, this study estimates the average values in each season to explore the spatial distribution characteristics of downward long wave radiation in the period from 2010 


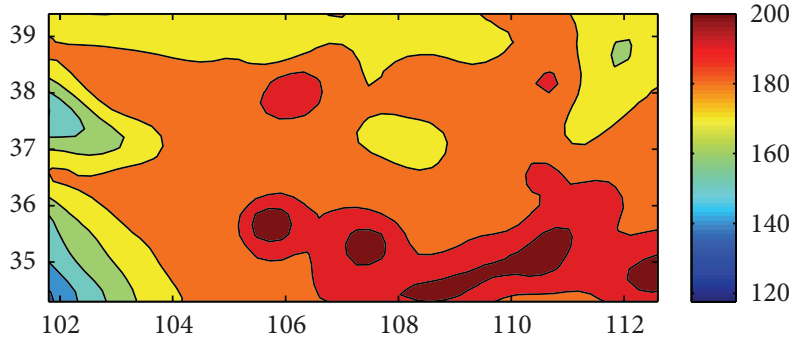

(a) Spring

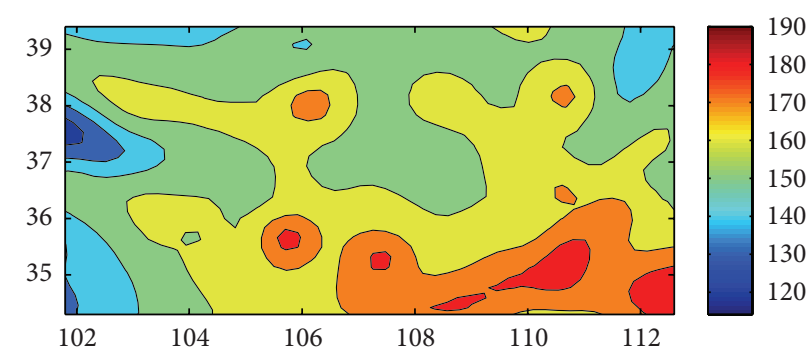

(c) Autumn

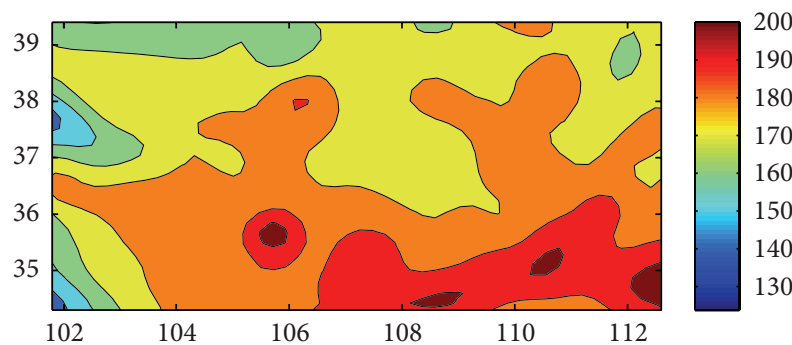

(a) Spring

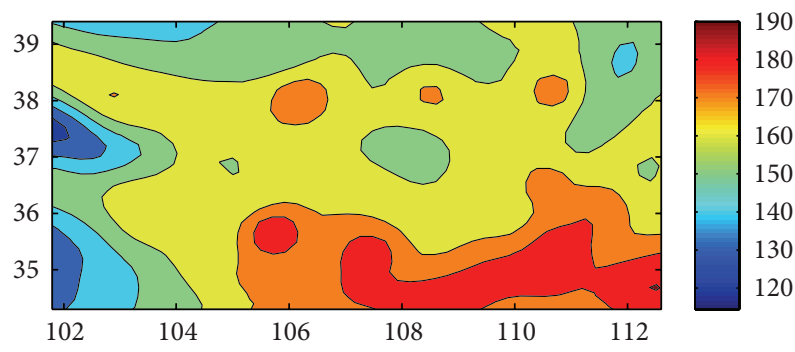

(c) Autumn

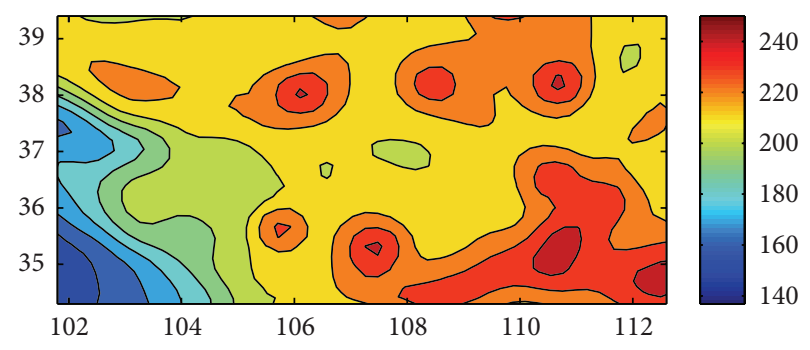

(b) Summer

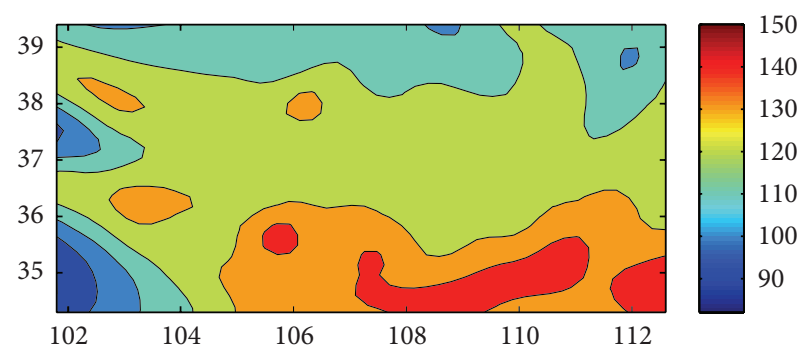

(d) Winter

$(2030)$

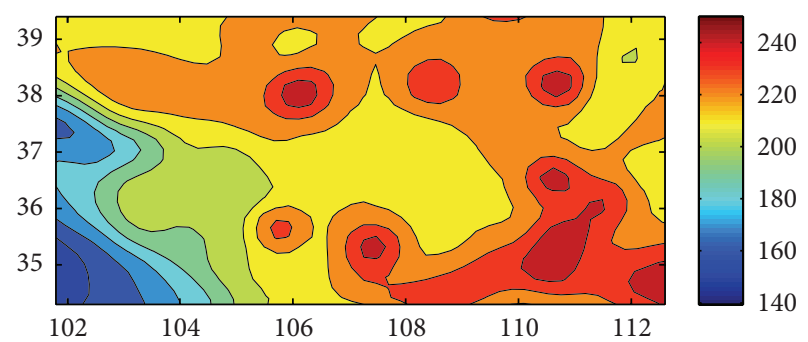

(b) Summer

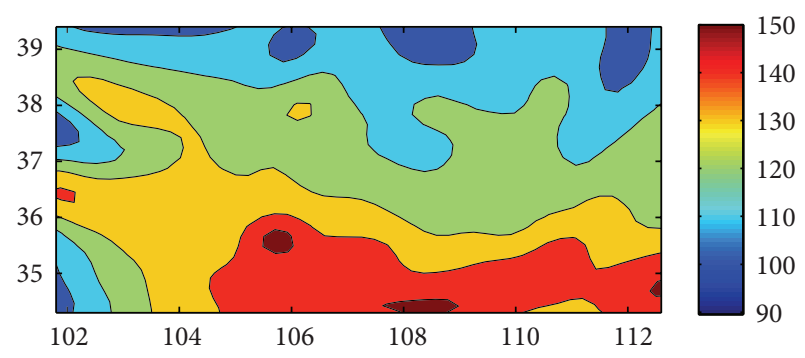

(d) Winter

(2050)

FIGURE 4: Downward long wave radiation in 2030 and 2050.

to 2050 (Figure 4). The results suggest that there is obvious variation in each season; however, the interannual differences are not significant. It is similar to the short wave radiation; summer has the highest downward long wave radiation which is about $213.5 \mathrm{~W} / \mathrm{m}^{2}$ in 2030 , followed by spring and autumn with $181.2 \mathrm{~W} / \mathrm{m}^{2}$ and $158.9 \mathrm{~W} / \mathrm{m}^{2}$, respectively. The lowest downward long wave radiation is in winter, which will fall down to $116.5 \mathrm{~W} / \mathrm{m}^{2}$ in 2030 .

Analysis on the spatial distribution of downward long wave radiation shows that it is higher in the central and southeastern regions and lower in the western regions without regarding the seasons. Comparing the spatial distribution of downward long wave radiation between four seasons, the regional disparity is small in spring and summer, while it is large in autumn and winter. Long wave radiation is also highest in summer, followed by spring. It is relatively lower in autumn and winter, especially in winter, reaching only half of that in summer.

The time scale analysis shows that the mean downward long wave radiation in the whole area varies within a narrow range from 2010 to 2050; it will change from $170.9 \mathrm{~W} / \mathrm{m}^{2}$ to $172.5 \mathrm{~W} / \mathrm{m}^{2}$ under the BAU scenario. Although the whole 


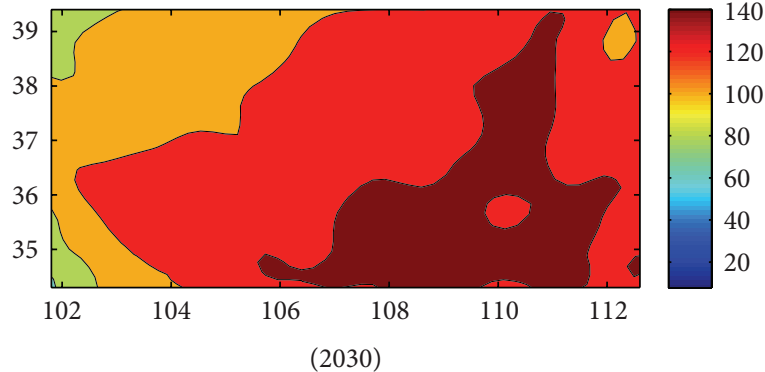

(a)

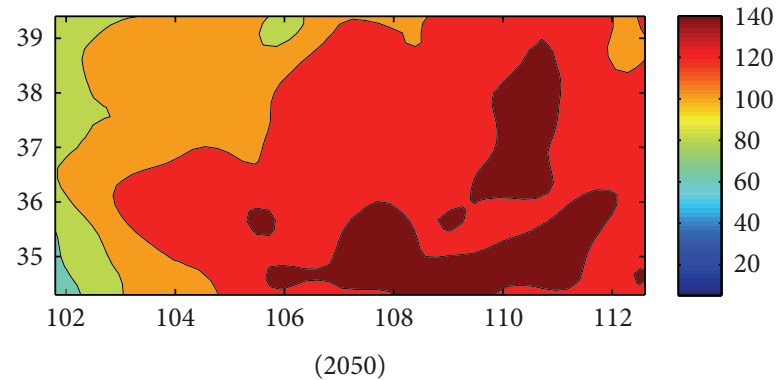

(b)

FIGURE 5: Net surface radiation in 2030 and 2050.

study area has small-scale growth, it has different changes in different seasons. It will fall down to some extent in spring and winter, while it will increase in summer and autumn especially in the north and middle of the semiarid grassland area of China from 2030 to 2050.

4.3. Net Surface Radiation. The monthly net surface radiation is estimated by the energy budget equation, and it is found that the barren or sparsely vegetated land in the western parts of Inner Mongolia Autonomous Region and northern Gansu Province has lower surface net radiation, while it is higher in the eastern and southeastern areas which are mostly covered by grassland, shrubland, cropland, and pasture (Figure 5). Although Qinghai Province is also covered by grassland, the high altitude and harsh growing conditions do not make the grassland grow as well as that in eastern study area. Therefore, the surface net radiation is lower. The time scale analysis shows that there is a decreasing trend from 2030 to 2050 especially in the southeast of study area, which illustrates that returning cropland to grassland and grassland restoration will decrease the net surface radiation.

\section{Discussion and Conclusion}

This study applies the DLS model to simulate the land cover from 2010 to 2050 under the BAU scenario. The spatial distribution of land cover in the study area has no disruptive changes from 2010 to 2050, and the changing ratio will gradually slow down. On the whole, the grassland shows a growing trend. Most of the increased grassland is converted from cropland or barren or sparsely vegetated land.

The regional energy balance in the semiarid grassland area of China is then analyzed through implementing the numerical simulation with the WRF model. Radiation is the main factor influencing the energy balance, so this study selects three indices representing the energy balance. The energy simulation results indicate that downward long wave radiation and downward short wave radiation will all have small-scale increase with time going by, while the net surface radiation will decrease from 2030 to 2050. However, the spatial disparity is extremely significant. There is obvious variation in each season; however, the interannual differences are not significant. Summer has the highest downward long wave radiation and short wave radiation, followed by spring and autumn, and the lowest are in winter.

The time scale analysis shows that downward short wave radiation in southern part of study area will increase in autumn and winter and there is no obvious change in the northern part from 2030 to 2050. However, it will show a growing trend in spring and summer. Land cover change also changes the surface energy. Returning cropland to grassland can reduce the downward short wave radiation, but the urban area and forestry area expansion can bring about more downward short wave radiation. As for the net surface radiation, there is obvious decrease in southeast of study area due to returning cropland to grassland. Therefore, it can be obtained that the land cover change and vegetation have strong relationship with surface energy; it is useful to strengthen the construction of ecological project and restore the ecological land. All of the results can be of great significance to select the reasonable land use mode to mitigate the regional climate change.

Although we have conducted estimation for the energy balance by the WRF model, there are certain limitations in our analysis. There is uncertainty on the prediction of land cover change; we cannot ensure that the developing trend is as same as the one in the history and the surface radiation will vary with the land cover change. In addition, this study just analyzes the surface radiation and does not involve the temperature and precipitation. Therefore, it is still necessary to carry out more in-depth research on the regional climate change.

\section{Conflict of Interests}

The authors declare that there is no conflict of interests regarding the publication of this paper.

\section{Acknowledgments}

This research was supported by the Fundamental Research Funds for the Central Universities (no. TD2011-03) and the National Major Scientific Research Program: The Decision Support System for the Integrated Water Resource Management in Heihe River Basin (HRB) (Grant no. 91325302). Data supports are from the National Key Programme for Developing Basic Science in China (Grant no. 2010CB950900). 


\section{References}

[1] C. M. Paiva, G. B. França, W. T. H. Liu, and O. C. Rotunno Filho, "A comparison of experimental energy balance components data and SEBAL model results in Dourados, Brazil," International Journal of Remote Sensing, vol. 32, no. 6, pp. 1731-1745, 2011.

[2] X. Lee, W. Massman, and B. Law, Handbook of Micrometeorology: A Guide for Surface Flux Measurement and Analysis, Kluwer Academic Publishers, New York, NY, USA, 2004.

[3] W. Yao, M. Han, and S. Xu, "Estimating the regional evapotranspiration in Zhalong wetland with the Two-Source Energy Balance (TSEB) model and Landsat7/ETM+ images," Ecological Informatics, vol. 5, no. 5, pp. 348-358, 2010.

[4] P. Lawrence and T. Chase, "Representing a new MODIS consistent land surface in the Community Land Model (CLM 3.0)," Journal of Geophysical Research, vol. 112, no. G1, 2007.

[5] R. A. Betts, "Biogeophysical impacts of land use on presentday climate: near-surface temperature change and radiative forcing," Atmospheric Science Letters, vol. 2, no. 1-4, pp. 1-13, 2001.

[6] J. M. Bosch and J. D. Hewlett, "A review of catchment experiments to determine the effect of vegetation changes on water yield and evapotranspiration," Journal of Hydrology, vol. 55, no. 1-4, pp. 3-23, 1982.

[7] E. Kalnay and M. Cai, "Impact of urbanization and land-use change on climate," Nature, vol. 423, no. 6939, pp. 528-531, 2003.

[8] R. Vose, T. Karl, D. Easterling, C. Williams, and M. Menne, "Impact of land-use change on climate," Nature, vol. 427, 213, p. 214, 2004.

[9] J. I. López-Moreno, S. M. Vicente-Serrano, E. Moran-Tejeda, J. Zabalza, J. Lorenzo-Lacruz, and J. M. García-Ruiz, "Impact of climate evolution and land use changes on water yield in the ebro basin," Hydrology and Earth System Sciences, vol. 15, no. 1, pp. 311-322, 2011.

[10] J. A. Foley, R. DeFries, G. P. Asner et al., "Global consequences of land use," Science, vol. 309, no. 5734, pp. 570-574, 2005.

[11] IHDP, "Urbanize and global environment change," International Human Dimensions Programme on Global Environmental Change, Germany, 2005.

[12] M. Liu, H. Tian, G. Chen, W. Ren, C. Zhang, and J. Liu, "Effects of land-use and land-cover change on evapotranspiration and water yield in China during 1900-2000," Journal of the American Water Resources Association, vol. 44, no. 5, pp. 1193-1207, 2008.

[13] R. A. Betts, P. D. Falloon, K. K. Goldewijk, and N. Ramankutty, "Biogeophysical effects of land use on climate: model simulations of radiative forcing and large-scale temperature change," Agricultural and Forest Meteorology, vol. 142, no. 2-4, pp. 216233, 2007.

[14] N. Christidis, P. A. Stott, G. C. Hegerl, and R. A. Betts, "The role of land use change in the recent warming of daily extreme temperatures," Geophysical Research Letters, vol. 40, no. 3, pp. 589-594, 2013.

[15] K. L. Findell, E. Shevliakova, P. C. D. Milly, and R. J. Stouffer, "Modeled impact of anthropogenic land cover change on climate," Journal of Climate, vol. 20, no. 14, pp. 3621-3634, 2007.

[16] K. B. Wilson, P. J. Hanson, P. J. Mulholland, D. D. Baldocchi, and S. D. Wullschleger, "A comparison of methods for determining forest evapotranspiration and its components: sap-flow, soil water budget, eddy covariance and catchment water balance," Agricultural and Forest Meteorology, vol. 106, no. 2, pp. 153-168, 2001.
[17] B. Güneralp and K. C. Seto, "Environmental impacts of urban growth from an integrated dynamic perspective: a case study of Shenzhen, South China," Global Environmental Change, vol. 18, no. 4, pp. 720-735, 2008.

[18] R. A. Pielke Sr., G. Marland, R. A. Betts et al., "The influence of land-use change and landscape dynamics on the climate system: relevance to climate-change policy beyond the radiative effect of greenhouse gases," Philosophical Transactions of the Royal Society A Mathematical, Physical and Engineering Sciences, vol. 360, no. 1797, pp. 1705-1719, 2002.

[19] S. Bathiany, M. Claussen, V. Brovkin, T. Raddatz, and V. Gayler, "Combined biogeophysical and biogeochemical effects of largescale forest cover changes in the MPI earth system model," Biogeosciences, vol. 7, no. 5, pp. 1383-1399, 2010.

[20] S. Kang, "Calculating method of potential atmospheric evaporation in the arid and semiarid areas," Agriculture Research in the Arid Areas, vol. 1, no. 2, pp. 41-50, 1985 (Chinese).

[21] G. Xua and M. Kanga, "Adaptation to the policy-oriented livelihood change in Xilingol grassland, Northern China," Procedia Environmental Sciences, vol. 3, pp. 1668-1683, 2012.

[22] J. Fan, H. Zhong, W. Harris et al., "Carbon storage in the grasslands of China based on field measurements of above- and below-ground biomass," Climatic Change, vol. 86, no. 3-4, pp. 375-396, 2008.

[23] J. Charney, W. J. Quirk, S. Chow, and J. Kornfield, "A comparative study of the effects of albedo change on drought in semiarid region," Journal of the Atmospheric Sciences, vol. 34, no. 9, pp. 1366-1385, 1977.

[24] J. Clarke, "Effect of drought stress on residual transpiration and its relationship with water use of wheat," Canadian Journal of Plant Science, vol. 1, no. 3, pp. 695-702, 2000.

[25] P. J. Lawrence and T. N. Chase, "Investigating the climate impacts of global land cover change in the community climate system model," International Journal of Climatology, vol. 30, no. 13, pp. 2066-2087, 2010.

[26] M. A. Hernández-Ceballos, J. A. Adame, J. P. Bolívar, and B. A. De la Morena, "A mesoscale simulation of coastal circulation in the Guadalquivir valley (southwestern Iberian Peninsula) using the WRF-ARW model," Atmospheric Research, vol. 124, pp. 1-20, 2013.

[27] M. Mohan and S. Bhati, "Analysis of WRF model performance over subtropical region of Delhi, India," Advances in Meteorology, vol. 2011, Article ID 621235, 13 pages, 2011.

[28] Z. Tao, J. A. Santanello, M. Chin et al., "Effect of land cover on atmospheric processes and air quality over the continental United States-a NASA Unified WRF (NU-WRF) model study," Atmospheric Chemistry and Physics, vol. 13, no. 13, pp. 62076226, 2013.

[29] X. Deng, Q. Jiang, H. Su, and F. Wu, "Trace forest conversions in Northeast China with a 1-km area percentage data model," Journal of Applied Remote Sensing, vol. 4, no. 1, Article ID 041893, 2010.

[30] X. Deng, Q. Jiang, J. Zhan, S. He, and Y. Lin, "Simulation on the dynamics of forest area changes in Northeast China," Journal of Geographical Sciences, vol. 20, no. 4, pp. 495-509, 2010. 

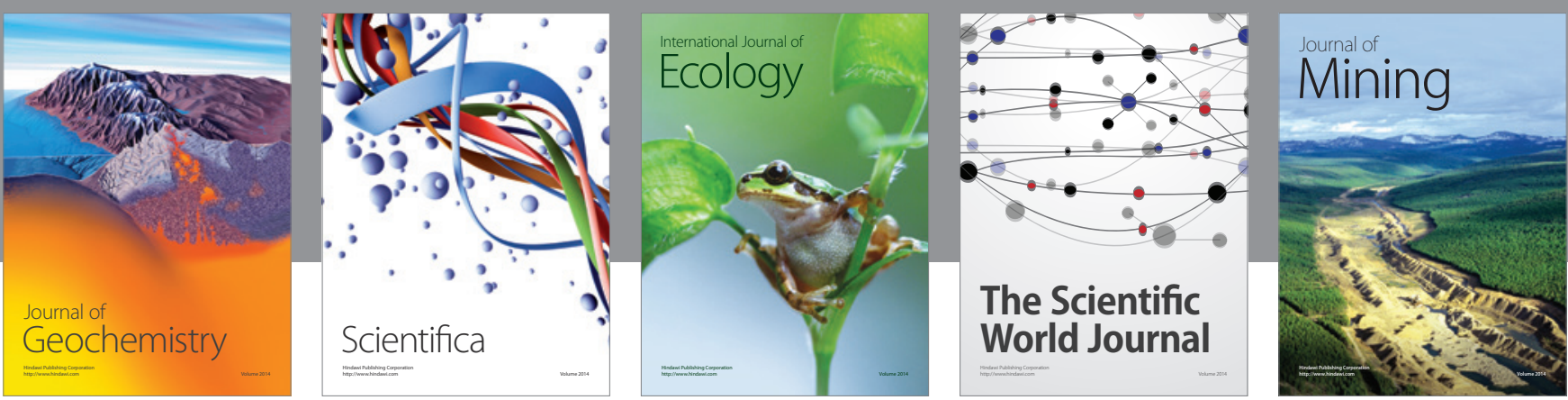

The Scientific World Journal
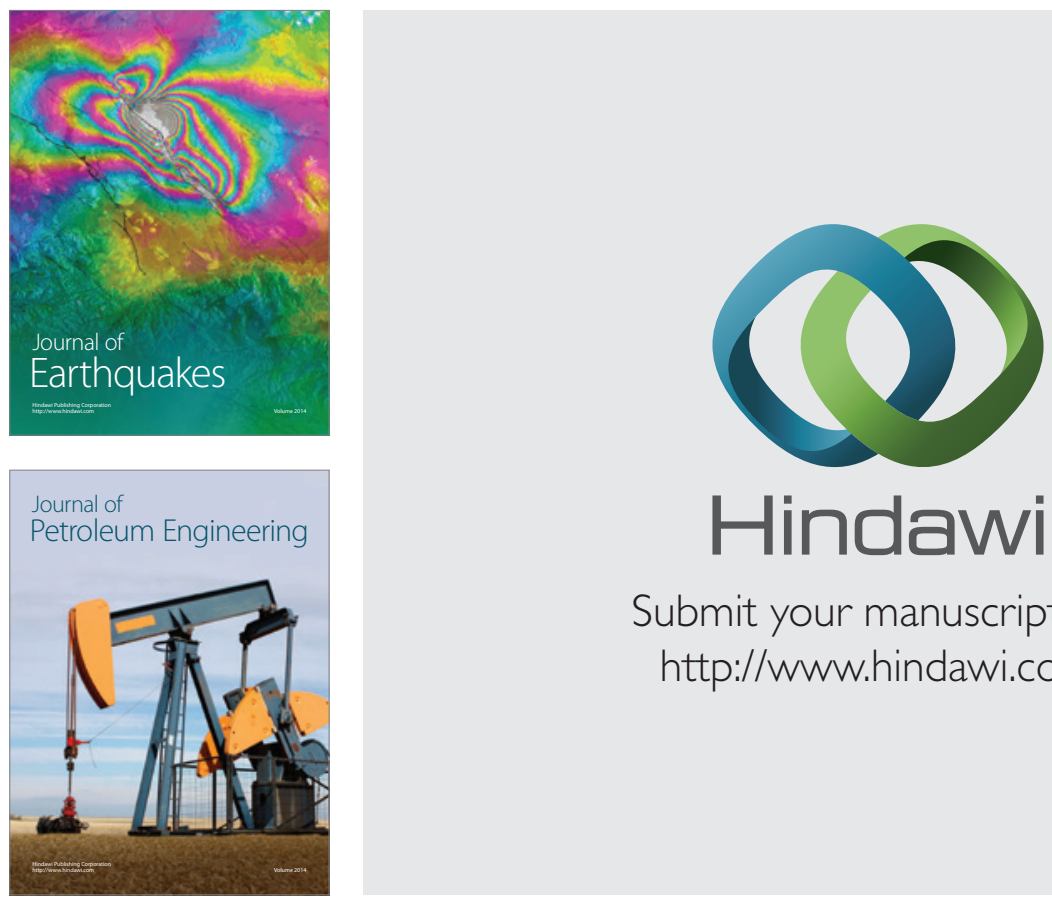

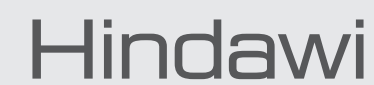

Submit your manuscripts at

http://www.hindawi.com
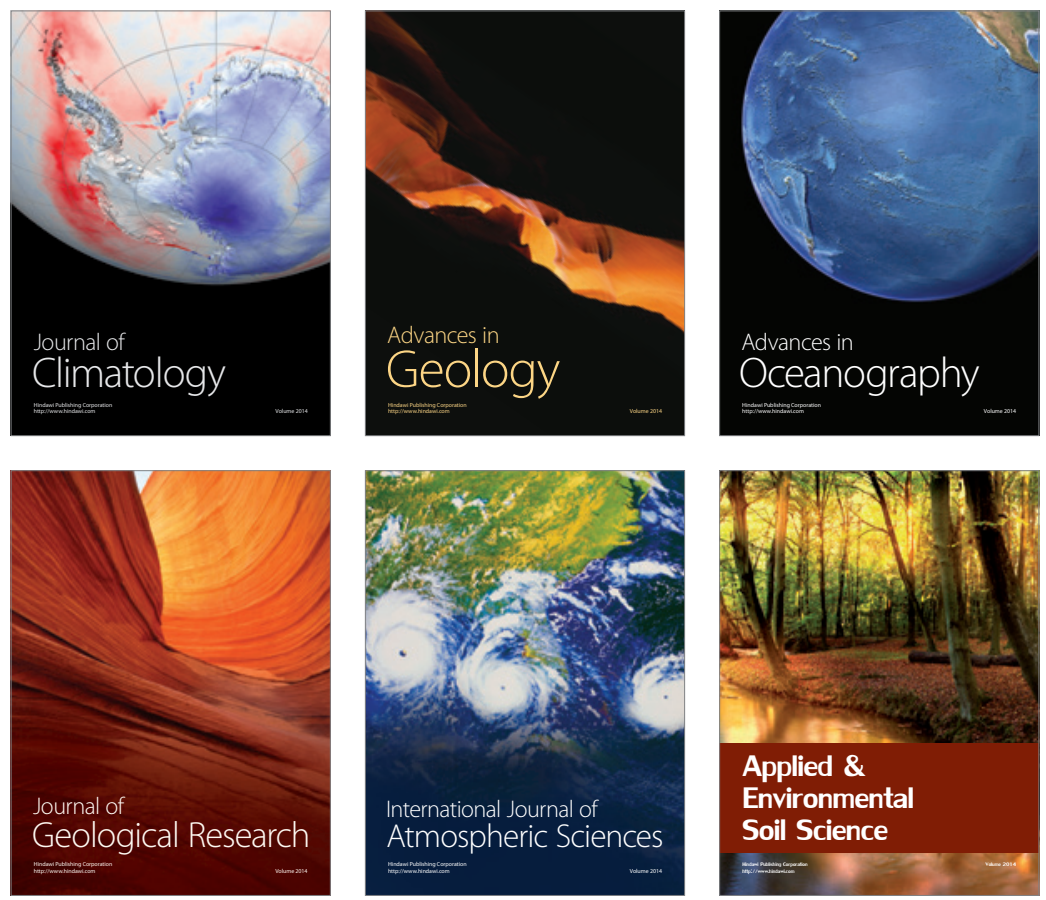
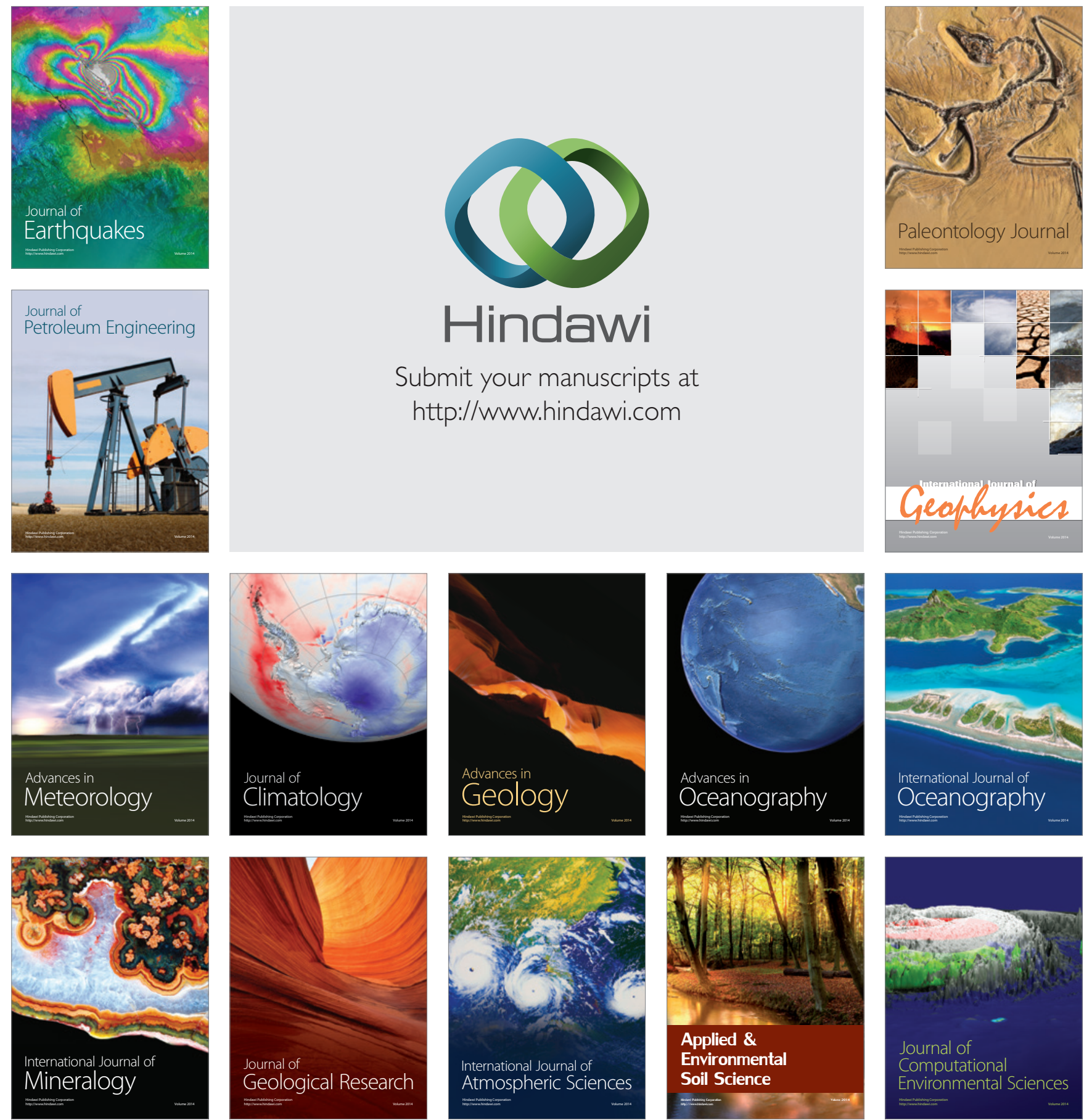